\title{
Comparison of fasting blood sugar between patients with schizophrenia and control group Mohsen Maroufi ${ }^{* 1}$, Faranak Kianvash ${ }^{2}$ and Mehran Mohamadi ${ }^{1}$
}

Address: ${ }^{1}$ Isfahan University of Medical Sciences, Behavioral Science Research Center, Iran and ${ }^{2}$ Oil Company Health Service

* Corresponding author

from International Society on Brain and Behaviour: 2nd International Congress on Brain and Behaviour

Thessaloniki, Greece. 17-20 November 2005

Published: 28 February 2006

Annals of General Psychiatry 2006, 5(Suppl I):SI85 doi:I0.1 186/I744-859X-5-SI-SI85

\section{Background}

Schizophrenia is a chronic mental disorder with unknown etiology. It seems that many endocrine and metabolic abnormalities are present in the schizophrenic patients. This study was done to determine the rate of abnormal plasma glucose levels in schizophrenic patients.

\section{Materials and methods}

Thirty two schizophrenic patients (16 male and 16 female) encountered in a cross-sectional descriptive survey. The fasting glucose levels of the patients were compared with normal subjects. For comparison of data, student's t. test was used.

\section{Results}

Five of the subjects in the patients group had impaired fasting glucose tolerance as defined by the American Diabetic Association Criteria (110-125 mg./dl.) In the control group, on the other hand, only 1 person had impaired fasting glucose tolerance $(\mathrm{p}=0.015)$

\section{Discussion}

According to the results of this study, and also some others, it seems that abnormal levels of glucose are more common in schizophrenics than total population. It is strongly recommended that patients with schizophrenia be carefully examined for diabetes mellitus or abnormal glucose tolerance.

\section{References}

I. Marder SR, Essock SM, Miller AM: Physical health monitoring of patients with schizophrenia. Am J Psychiatry 2004, 161:1334-1349.

2. Dinan T, Peveler R, Holt R: Understanding schizophrenia and diabetes. Hosp Med 2004, 65:485-458.

3. Thakore $\mathrm{JH}$ : Metabolic disturbance in first-episode schizophrenia. BrJ Psychiatry Suppl 2004, 47:S76-S79.
4. Lindenmayer JP: Changes in glucose level in patients with schizophrenia. Am J Psychiatry 2003, 160:290-296. 